\title{
Voices from the coalface
}

\section{EDITORIAL}

\section{Moyez Jiwa}

Melbourne Clinical School, The University of Notre Dame Australia, Werribee, VIC, Australia

To Cite: Jiwa M. Voices from the coalface.

2019;4(2):182-185.

https://doi.org/10.21853/JHD.2019.87

\section{Corresponding Author:}

Moyez Jiwa

Melbourne Clinical School

School of Medicine

The University of Notre Dame, Australia

300 Princes Highway, Werribee, VIC, 3030

Australia

\section{Copyright:}

(c) 2019 The Authors. Published by Archetype Health

Pty Ltd. This is an open access article under the CC

BY-NC-ND 4.0 license.

\section{SUMMARY}

In this editorial I review the key themes of the conversations recorded with a distinguished panel of guests who were interviewed as part of The Health Design podcast series. The guests focused on the promise of the creativity of brilliant young people given opportunities; the vital importance of the human side of health care; working with communities to solve local problems; and how the pursuit of profits has eroded health care.

\section{Key Words}

health care; health care profits; creativity; health design; humanity in health care

\section{INTRODUCTION}

As a society we eat too much, drink too much alcohol, don't exercise enough, and accordingly, long-term lifestylerelated illnesses are becoming more common. Not surprisingly, people are experiencing poorer health. What's more, we are paying more for health care than is necessary. Thus far our efforts at improving health have been disappointing. Our ingenuity hasn't been focused on the fundamental reason that people seek help in the first place. When we are sick we are seeking relief from our pain-be it physical or psychological. The experience of pain is a deeply personal phenomenon. A one-size-fits-all approach neatly packaged in a blister pack or under a surgeon's knife may seem appealing but often fails and is now increasingly unaffordable or giving rise to other problems. In countries where more is spent on health care, notably the United States, outcomes are not better than where other governments spend proportionally less. In 2018, The Journal of Health Design established a podcast series, The Health Design podcast, that has featured many high-profile guest interviews. In this editorial, I review some of these conversations and the stories told that tell us so much about those who are leading the drive to improve health care globally.

\section{Creativity}

The first selections of these conversations that I have selected to review give us the most hope. We are fortunate that there are young people like Dr Marc Succi, a radiologist and entrepreneur, and Sam Mazin, co-founder and chief technology officer of RefleXion Medical, who are investing their intellectual brain power to finding technological solutions for problems that cannot be addressed with the tools available to us today. Marc Succi is a medical graduate from Harvard. ${ }^{1}$ His experience tells us that schools like Harvard produce brilliant graduates because they invest in their students' creativity. He and his peers were encouraged to take a year out of their medical training to do research or a business degree to become "a better rounded clinician". Marc's exploration of the ideas that he subsequently patented and commercialised were framed as a creative exercise. During the time way from the wards he started his own company, 2 Minute Medicine, to make published science more accessible to doctors. A key message in Marc's interview was that he has learned to create solutions for real problems, not wait till later to think about problems that might benefit from his innovations. So, a critical point in his work is to understand the patient's perspective but also to enjoy the challenge as an intellectual pursuit. Similar views were expressed by Sam Mazin whose company RefleXion Medical has developed technology that will better disclose cancers so that they can be targeted for treatment. ${ }^{2}$ Sam's interest in mathematics led him to study computer engineering, then medical engineering, which led to the breakthroughs that may render metastatic cancer, such as his aunt contracted, to be treatable in the foreseeable future. 


\section{Elevating the human side to health care}

Perhaps my favorite conversations were with those who spoke about delivering health care. Jake Poore worked at Disney for many years and now devotes his enormous energy to elevating the human side of health care. ${ }^{3}$ Referencing the tragic story of his own father, he demonstrated how when healthcare practitioners take small details for granted seemingly insignificant acts of omission or commission can lead to catastrophe and even death. Jake's humanity and wonderful skill as a communicator, including his insight into what makes a good experience at Disney, suggest that it is in the small acts of kindness that we can improve the patient experience while also ensuring the best results in many cases. Along the same lines, Amy Willans spoke about her experience of being treated for mental illness and how a small act of kindness during one episode of hospitalisation boosted her recovery and changed the trajectory of her life. Amy is now a spokesperson for people living with mental illness in her community. ${ }^{4}$ Meanwhile, Deborah Heiser focused on reframing our view of older people. ${ }^{5}$ She started by discussing the challenge of caring for older people and specifically about what can be learned from visiting their homes. Deborah noted that often the reasons why older people end up in hospital can be prevented with relatively simple, temporary measures to make life more tolerable in the community. Deborah also spoke about the Mentor Project, which is about enabling older people to contribute by offering them the opportunity to engage constructively younger generations and at the same time leave a legacy.

\section{Working with communities}

Glenn Llopis started his interview mentioning the 'standardisation trap' in health care. ${ }^{6}$ Warning that we cannot continue to treat people as if they all faced the same challenges, Glenn pointed out that despite the rhetoric consumers haven't really been in control of their health care. As a greater range of providers have come on the scene it has become apparent that people want more control. We now stand at a cross crossroads. In the past the consumer had to accept whatever was on offer. In the new paradigm health care will become a customer experience leader in a world where the needs of the population will change in keeping with unprecedented changes in population profile. Meanwhile, Stephen Brown, director of preventive emergency medicine at University of Illinois Hospital, in Chicago, Illinois, US, pointed out that people don't come back to overcrowded emergency departments in a vaccum. ${ }^{7}$ By understanding their context the team are better able to reduce repeat visits to the department. As a health professional Stephen tells the story of a patient who suffers intrusive thoughts because of some background trauma and takes illicit drugs to make life bearable. By focusing on the structural violence that drives patients to self-destructive behaviours it is possible to reduce the use of emergency health care in the city of Chicago. The solution is sometimes to provide more responsive housing for people who find themselves homeless having been ejected from elsewhere because of their challenging behaviours. Focusing on the issues that drive poor outcomes, specifically early childhood experience in poorer communities, it has been possible to record improvements in the subsequent outcomes in health care. In a similar vein, Lloyd Michener from Duke University's Center for Community Research spoke about the importance of looking at the environment and working with the community to build localities where many of the key determinants of health can be addressed. ${ }^{8}$ Llyod's call is for professionals to work more closely to identify targeted and precise solutions for clusters of people who have the worst outcomes.

\section{The pursuit of profits}

Two of our guests spoke passionately about the need for caution in the solutions we generate, especially in the pursuit of profits. Deborah Peel, who retired after a distinguished career in psychiatry outlined the history of how privacy has been sequentially undermined through time, especially in the USA. ${ }^{9}$ She recognised from the work of her data scientist father and from her own insights that it was possible to identify any individual from the data that is routinely gathered in health care. She spoke about how various administrations of the US government gradually allowed privacy to be stripped by removing the need for patient consent for much of the data collected by government and other agencies. Deborah describes how it is now trivially easy to identify individuals from what may be labelled de-identified information. The concern is that in the drive to make profits by collecting increasing amount of data about individuals it may be possible for an insurer to identify those who pose a greater risk, and such individuals may find themselves 
discriminated against even before they become ill. Marion Mass, also a clinician and a seasoned advocate for patient rights, described how health care costs in the US are inflated not by the actual cost of that care but by payments to those who are paid for services to health departments while holding staggering conflicts of interest. ${ }^{10}$

The Health Design podcast series has explored topics that are part of the International Association of Health Design's key pillars:

1. Accessible health care for all

2. Valuing the perspectives of those who seek health care

3. Sustaining the performance of those involved in caring for people

4. Focusing on small changes that improve outcomes for people in health care today

5. Highlighting the contribution of design and architecture in the care of those who seek health care.

Our guests have further developed these themes and demonstrated that there is a great deal yet to be done to make this vision a reality. Thoughtful acts of kindness make an enormous difference in the art of doctoring; we must seek the perspective of those who need health care because often the solutions are not those doled out in pills; designers and those who encourage creativity are generating solutions to problems that we may consider hopeless today; and the pursuit of profits may undermine the value we seek to create. At the JHD we look forward to continuing the conversation with others who have explored these issues or have developed solutions in the context of their clinical practice.

\section{REFERENCES}

1. Succi M. Marc Succi Interview. The Health Design Podcast. [podcast on the Internet]. Melbourne, VIC: Archetype Health Party, Ltd; 2018 [cited 2018 Jun 26]. Available from: https://soundcloud.com/user-499494424/marc-succiinterview

2. Mazin S. Sam Mazin Interview. The Health Design Podcast. [podcast on the Internet]. Melbourne, VIC: Archetype Health Party, Ltd; 2018 [cited 2018 Jun 26]. Available from: https://soundcloud.com/user-499494424/sam-mazininterview

3. Poore J. Jake Poore Interview. The Health Design Podcast. [podcast on the Internet]. Melbourne, VIC: Archetype Health Party, Ltd; 2018 [cited 2018 Jun 26]. Available from: https://soundcloud.com/user-499494424/jake-pooreinterview

4. Willans A. Amy Willans Interview. The Health Design Podcast. [podcast on the Internet]. Melbourne, VIC: Archetype Health Party, Ltd; 2018 [cited 2018 Jun 26]. Available from: https://soundcloud.com/user499494424/amy-willans-interview

5. Heiser D. Deborah Heiser Interview. The Health Design Podcast. [podcast on the Internet]. Melbourne, VIC: Archetype Health Party, Ltd; 2018 [cited 2018 Jun 26]. Available from: https://soundcloud.com/user499494424/deborah-heiser-interview)

6. Llopis G. Glenn Llopis interview. The Health Design Podcast. [podcast on the Internet]. Melbourne, VIC: Archetype Health Party, Ltd; 2018 [cited 2018 Jun 26]. Available from: https://soundcloud.com/user499494424/glenn-1lopis-interview

7. Brown S. Stephen Brown Interview. The Health Design Podcast. [podcast on the Internet]. Melbourne, VIC: Archetype Health Party, Ltd; 2018 [cited 2018 Jun 26]. Available from: https://soundcloud.com/user499494424/stephen-brown-interview

8. Michener JL. James Lloyd Michener Interview. The Health Design Podcast. [podcast on the Internet]. Melbourne, VIC: Archetype Health Party, Ltd; 2018 [cited 2018 Jun 26]. Available from: https://soundcloud.com/user499494424/james-lloyd-michener-interview

9. Peel D. Deborah Peel Interview. The Health Design Podcast. [podcast on the Internet]. Melbourne, VIC: Archetype Health Party, Ltd; 2018 [cited 2018 Jun 26]. Available from: https://soundcloud.com/user-499494424/deborahpeel-interview 
10. Mass M. Marion Mass Interview. The Health Design Podcast. [podcast on the Internet]. Melbourne, VIC: Archetype Health Party, Ltd; 2018 [cited 2018 Jun 26]. Available from: https://soundcloud.com/user499494424/marion-mass

\section{ACKNOWLEDGEMENTS}

I would like to thank all of The Health Design podcast guests referenced in this editorial, as well as the many others who have generously shared their time and their stories. I appreciate the great work and continued efforts to improve the health care and patient experience.

\section{PEER REVIEW}

Commissioned. Not externally peer reviewed.

\section{CONFLICTS OF INTEREST}

The authors is the editor in chief of the JHD.

\section{FUNDING}

$\mathrm{N} / \mathrm{A}$

ETHICS COMMITTEE APPROVAL

$\mathrm{N} / \mathrm{A}$

\section{FIGURES AND TABLES}

$\mathrm{N} / \mathrm{A}$ 